\title{
Left Atrial Myxoma With Concurrent Saddle Pulmonary Embolism and Duke's B Colorectal Adenocarcinoma
}

\author{
Sonal Mehra ${ }^{\mathrm{a}}$, Yasir Parviz ${ }^{\mathrm{b}, \mathrm{c}}$, Abdallah Al-Mohammad
}

\begin{abstract}
A 64-year-old male with previous Duke's B adenocarcinoma of the colon, successfully treated with surgery and chemotherapy presented several months later with dyspnoea and atrial fibrillation. Investigations showed that he had a left atrial myxoma and a concurrent saddle pulmonary embolus. Full anticoagulation with unfractioned heparin was administered followed by surgical resection of the myxoma. Links between pulmonary emboli and underlying carcinoma are well established. However, to our knowledge, this is only the second case in the English literature where a patient has had both an adenocarcinoma of the colon and a myxoma. There are no links between a pulmonary saddle embolism and left atrial myxoma or between a right sided myxoma and a pulmonary saddle embolus and where the embolism is not a fragment of the myxoma.
\end{abstract}

Keywords: Myxoma; Pulmonary embolism; Colorectal adenocarcinoma; Echocardiography; Cardiothoracic surgery

\section{Introduction}

Cardiac masses can be tumors (primary or secondary), thrombus and/or vegetations.

We report a case with the possibility of all three co-existing together in a single patient with a known primary cancer of the colon, lesions in the liver, the possibility of metastasis to the heart and a high risk of thromboembolism. We would

\footnotetext{
Manuscript accepted for publication April 25, 2013

${ }^{\text {a }}$ Sheffield Teaching Hospitals, Northern General Hospital, Herries Road, Sheffield S5 7AU, UK

${ }^{\mathrm{b}}$ Department of Cardiology, Sheffield Teaching Hospitals, Northern General Hospital, Herries Road, Sheffield S5 7AU, UK

${ }^{\mathrm{c} C}$ Corresponding author: Yasir Parviz, Sheffield Teaching Hospitals, Northern General Hospital, Herries Road, Sheffield S5 7AU, UK. Email: dr1yasir@hotmail.com
}

doi: http://dx.doi.org/10.4021/jmc1243w like to highlight the importance of these differential diagnoses of cardiac masses in every individual case.

Co-existence of atrial myxoma with saddle pulmonary embolism (PE) and adenocarcioma of the colon can affect the heart by a number of different mechanisms; increasing cardiovascular demands on the heart, arrhythmias, structural change of the heart and promoting cardiovascular disease. As clinicians we need to manage clinical conditions in order of priority for best clinical outcome.

\section{Case Report}

A 64-year-old man presented to the local district general hospital with lethargy and generally feeling unwell. On examination, his right leg was swollen. The patient then developed chest pain, haemoptysis and atrial fibrillation (AF) and was referred to our institution. Past medical history is significant for Duke's stage B colorectal adenocarcinoma treated 6 months earlier with anterior resection and chemotherapy. He was waiting for resection of two isolated liver lesions revealed on a follow-up staging computed tomography (CT) and positron emission tomography (PET).

An ultrasound Doppler confirmed a right femoral deep vein thrombosis (DVT). An echocardiogram, performed due to the AF (Fig. 1) showed a mass in the left atrium (LA). Of note no cardiac mass was detected on the previous PET or CT scan 6 months prior to this admission. A computed tomography pulmonary angiogram (CTPA) was done in view of the DVT and haemoptysis, and revealed a saddle pulmonary embolus (PE) with extensive thromboembolism affecting the pulmonary arterial tree to the periphery of the pulmonary circulation (Fig. 2). The coronary angiogram was normal.

Due to previous history of adenocarcinoma, the initial differential diagnosis consisted of secondary metastases, primary cardiac tumour or thrombus in the heart. It was difficult to establish whether the entire cardiac mass was a thrombus or a myxoma. Although the saddle PE was most likely an embolized thrombus related to his DVT, the possibility of an embolized tumour fragment had to be considered.

The patient's AF (180 bpm) was rate-controlled, and he 


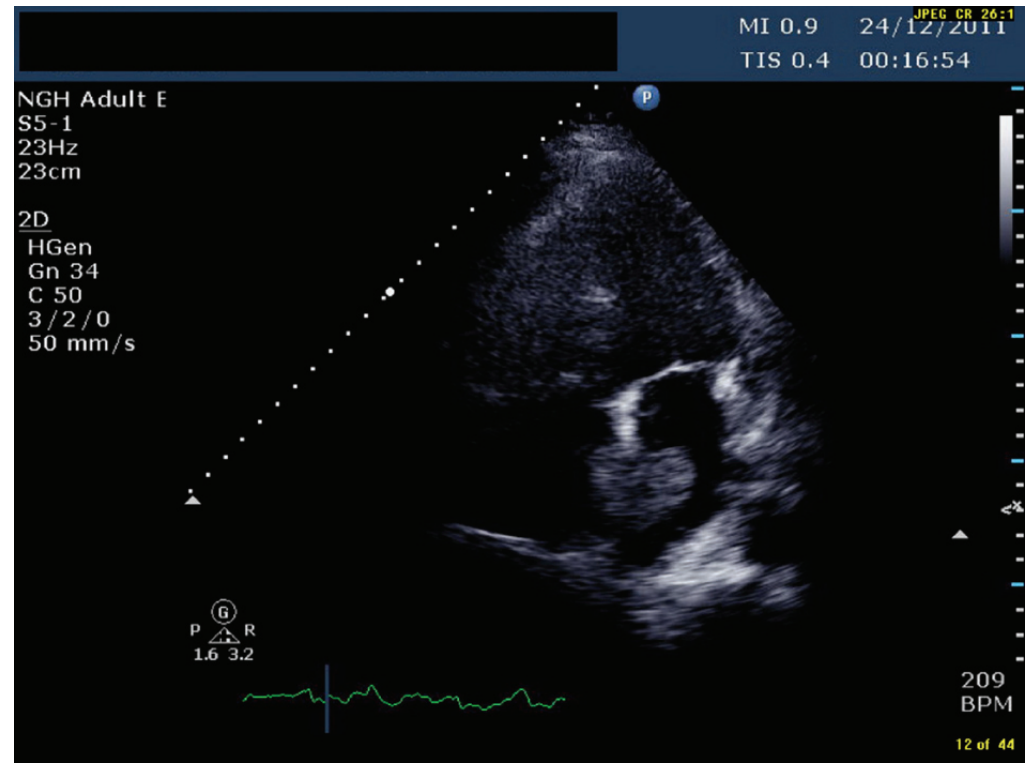

Figure 1. TTE (transthoracic echocardiogram) showing a pedunculated mass in left atrium measuring $1.96 \mathrm{~cm} \times 3.45 \mathrm{~cm}$

was started with unfractionated heparin intravenous (IV) infusion. Thrombolysis for the PE was not indicated in this case as circulatory collapse was not imminent. The saddle PE was no longer present after several days of heparin whereas the mass in the LA remained. Following discussion with the cardiothoracic team, surgery was postponed until the patient's $\mathrm{AF}$ was adequately controlled and pulmonary circulation had improved. Cardiac surgery was undertaken 2 weeks later, and confirmed the presence of a rounded nodular brown and beige tumour $38 \times 28 \times 25 \mathrm{~mm}$. Histology showed a rounded/polypoid lesion, comprising mainly laminated fibrin/necrotic matter. Towards the base of the lesion, and immediately above some myocardial tissue was an area of loose myxoid matrix with some vascular proliferation, strongly suggestive of a cardiac myxoma, although classic features were not seen. Local excision was regarded as complete.

The patient recovered well after surgery with no postoperative complications and was discharged a week later on warfarin. 5 months later the patient had successful resection of the liver nodules, confirmed as metastatic colon adenocarcinoma. At present the patient is currently free from myxoma, recurrence of the adenocarcinoma and further venous thromboembolism (VTE).

\section{Discussion}

To our knowledge only one previous case of atrial myxoma with concurrent Duke's B2 adenocarcinoma of the colon exists in the English literature. In 1997 Nuno et al [1] described a 56-year-old male who presented with nearly obstructing adenocarcinoma, AF and a LA myxoma prolapsing through the mitral valve into the left ventricle (LV). In this case, the patient was treated with digoxin and IV unfractionated heparin and underwent cardiac surgery prior to having a resection of the colon and a partial cystectomy. The patient was fitted with a permanent pacemaker following ablation for AF.

Primary cardiac tumours are rare $(0.02-0.19 \%)$ [2-4]; myxoma is the commonest benign tumour in adults (45$50 \%$ ) [5]. Myxomas present between the ages of $30-70$ years, and occur more frequently in women $[5,6]$. The majority of myxomas $(75-90 \%)$ originate in the LA from the fossa ovalis [5-7]. Clinical features include dyspnoea, syncope, arrhythmias, oedema, haemoptysis, and sudden death [2]. Systemic features of embolic phenomena (30-40\%) [8] can result in pulmonary embolism, stroke and vasculitis and can mimic infective endocarditis [5-8]. However, $10-15 \%$ of patients are asymptomatic when a mass is incidentally found on imaging [7-9]. Myxomas are thought to arise from undifferentiated and totipotent mesenchymal stem cells 5 and have a quick growth rate [8]. Most tumours are $5-6 \mathrm{~cm}(1-15$ $\mathrm{cm})$ in diameter and weigh an average of 57 grams $(8-450$ g) [8-10].

Two-dimensional transthoracic echocardiography (TTE) is the first line investigation with sensitivity of $90 \%$ and a specificity of $95 \%$ [5]. On echocardiography heterogenicity and small lucencies are consistent with myxoma whereas thrombi are homogenous and are usually found in the left atrial appendage [2]. Myxomas carry a high embolic risk and surgical removal is the only curative option $[5,7,8,11,12]$. There is a $3 \%$ chance of recurrence, which increases to 12 - 


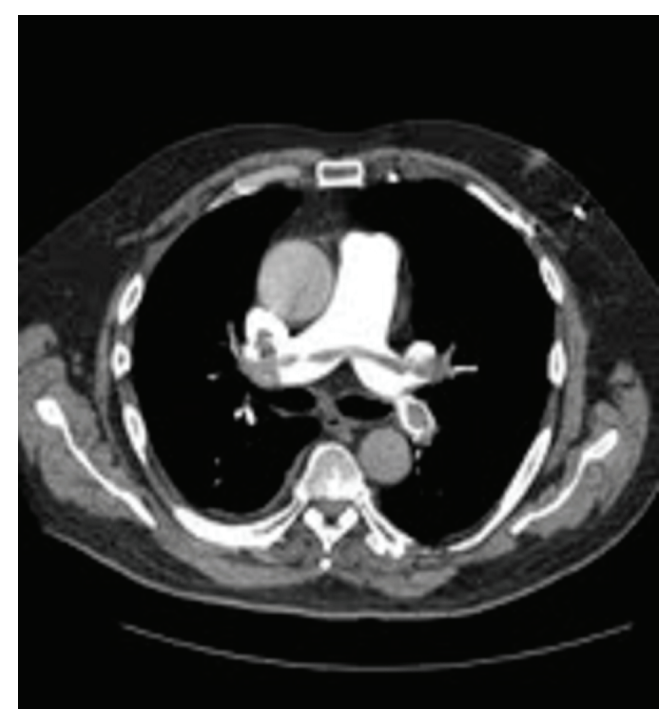

Figure 2. Computed tomography pulmonary angiogram (CTPA) showing saddle pulmonary embolism extending across both pulmonary arteries.

$22 \%$ for familial types; either as another primary myxoma or more commonly due incomplete surgical resection $[5,8$, $11,12]$.

Metastatic cardiac disease is more common than primary cardiac tumours. Autopsy-based studies show that between $1 \%$ and $20.5 \%$ of patients with extra-cardiac malignant tumours have metastases to the heart, most commonly occurring in widespread malignancy $[2,3,13]$. In up to $90 \%$ of these cases there would have been no clinical cardiac symptoms [2]. Cancer of the colon has been shown to give rise to sporadic cases of metastases to the heart [3, 14-17]. A literature search shows 14 known cases of cardiac metastases from colorectal adenocarcinoma, commonly to the right atrium/right ventricle $[15,16]$.

Colon cancer accounts for $12-14 \%$ of cancer cases in the UK and is mainly diagnosed in those over the age of 50 years, unless there is a genetic predisposition [18]. The majority are adenocarcinoma (95\%) and arise from the left side of the colon [18]. The liver is the most common site of metastases $(45 \%)[18,19]$. Overall survival from colon cancer is approximately $60 \%$ at 5 years. If metastases are present, then life expectancy is at an average of 12 - 18 months. However, attitudes towards liver resections for metastases have changed and if the metastases are isolated within one lobe or quadrant, then surgery is performed even if multiple metastases are present [20]. This improves the 5 year survival rates in those with liver metastases from $0 \%$ to up to $33 \%[19,20]$.

Pulmonary embolism (PE) is common in those with underlying malignancy, with the risk of thrombosis increased by 4.1 fold $[21,22]$. Colon cancer has been shown to have risk of PE of $1-3.1 \%[22,23]$. The highest incidence of a VTE is within the first 6 months of diagnosis compared to after 2 years; $5 \%$ and $0.6 \%$ respectively [22]. Patients with metastatic cancer and three or more other co-morbidities have a higher rate of VTE [22].

The main differential diagnoses for cardiac masses are tumour, both primary and secondary, thrombus and vegetation. In this case the possibility of multiple differential diagnoses existed; the patient had a known primary cancer of the colon with a metastatic nodule in the liver and a high risk of thromboembolism. Vegetations were less likely as there was no history of valvular lesions and imaging showed no significant regurgitation or vegetation. However endocarditis must be excluded for any cardiac masses.

In this case the PE was likely the result of the metastatic colon adenocarcinoma, and the myxoma was incidentally picked up on imaging. As the PE resolved and a mass, highly suspicious of myxoma, remained, surgical resection of the cardiac mass took priority over the liver nodules due to the risk of potentially fatal systemic circulatory embolism. However, before surgery the patient should be hemodynamically stable and in this case the ventricular response rate to $\mathrm{AF}$ was adequately controlled before attempting resection. After the cardiac myxoma was removed the patient's liver nodules continued to be monitored and an adequate recovery time was given prior to resection of the nodules.

\section{Patient Consent}

Obtained.

\section{Competing Interests}

None.

\section{Ethical Approval}

Not applicable.

\section{Funding}

Not applicable.

\section{References}

1. Nuno IN, Kang TYt, Arroyo H, Starnes VA. Synchronous cardiac myxoma and colorectal cancer: a case report. Tex Heart Inst J. 2001;28(3):215-217.

2. Shapiro LM. Cardiac tumours: diagnosis and management. Heart. 2001;85(2):218-222.

3. Reynen K, Kockeritz U, Strasser RH. Metastases to the 
heart. Ann Oncol. 2004;15(3):375-381.

4. O'Donnell DH, Abbara S, Chaithiraphan V, Yared K, Killeen RP, Cury RC, Dodd JD. Cardiac tumors: optimal cardiac MR sequences and spectrum of imaging appearances. AJR Am J Roentgenol. 2009;193(2):377-387.

5. Paraskevaidis IA, Michalakeas CA, Papadopoulous $\mathrm{CH}$ et al. Cardiac Tumours. ISRN Oncol Published Online First: 26 May 2011 doi:10.5402/2011/208929.

6. Sutsch G, Jenni R, von Segesser L, Schneider J. [Heart tumors: incidence, distribution, diagnosis. Exemplified by 20,305 echocardiographies]. Schweiz Med Wochenschr. 1991;121(17):621-629.

7. Rahmanian PB, Castillo JG, Sanz J, Adams DH, Filsoufi F. Cardiac myxoma: preoperative diagnosis using a multimodal imaging approach and surgical outcome in a large contemporary series. Interact Cardiovasc Thorac Surg. 2007;6(4):479-483.

8. Reynen K. Cardiac myxomas. N Engl J Med. 1995;333(24):1610-1617.

9. Pinede L, Duhaut P, Loire R. Clinical presentation of left atrial cardiac myxoma. A series of 112 consecutive cases. Medicine (Baltimore). 2001;80(3):159-172.

10. Hanson EC, Gill CC, Razavi M, Loop FD. The surgical treatment of atrial myxomas. Clinical experience and late results in 33 patients. J Thorac Cardiovasc Surg. 1985;89(2):298-303.

11. Ipek G, Erentug V, Bozbuga N, Polat A, Guler M, Kirali K, Peker O, et al. Surgical management of cardiac myxoma. J Card Surg. 2005;20(3):300-304.

12. Bakaeen FG, Reardon MJ, Coselli JS, Miller CC, Howell JF, Lawrie GM, Espada R, et al. Surgical outcome in 85 patients with primary cardiac tumors. Am J Surg. 2003;186(6):641-647; discussion 647.

13. Bussani R, De-Giorgio F, Abbate A et al Cardiac Metastases Review. 2006 www.jclinpath.com pages 27-34.

14. Makhija Z, Deshpande R, Desai J. Unusual tumours of the heart: diagnostic and prognostic implications. J Cardiothorac Surg. 2009;4(4.

15. Choi PW, Kim CN, Chang SH, Chang WI, Kim CY, Choi HM. Cardiac metastasis from colorectal cancer: a case report. World J Gastroenterol. 2009;15(21):26752678.

16. Patel SA, Herfel BM, Nolan MA. Metastatic colon cancer involving the right atrium. Tex Heart Inst J. 2012;39(1):79-83.

17. Parravicini R, Fahim NA, Cocconcelli F, Barchetti M, Nafeh M, Benassi A, Grisendi A, et al. Cardiac metastasis of rectal adenocarcinoma. Surgical treatment. Tex Heart Inst J. 1993;20(4):296-298.

18. Brounts LR, Zulu R, Steele SR Colon Cancer: Review First accessed on 16/10/12 http://www.ptolemy.ca/members/archives/2008/ColonC/index.htm\#t 10.

19. Sahani DV, Kalva, SP, Fischman AJ Detection of Liver Metastases from Adenocarcinoma of the Colon and Pancreas: Comparison of Mangafodipir TrisodiumEnhanced Liver MRI and Whole-Body FDG PET Am J Roentgenol 2005;185:239-246.

20. Nordlinger B, Rougier P. Liver metastases from colorectal cancer: the turning point. J Clin Oncol. 2002;20(6):1442-1445.

21. Lee AY, Levine MN. Venous thromboembolism and cancer: risks and outcomes. Circulation. 2003;107(23 Suppl 1):I17-21.

22. Alcalay A, Wun T, Khatri V, Chew HK, Harvey D, Zhou $\mathrm{H}$, White RH. Venous thromboembolism in patients with colorectal cancer: incidence and effect on survival. J Clin Oncol. 2006;24(7):1112-1118.

23. Read TE, Mutch MG, Chang BW, McNevin MS, Fleshman JW, Birnbaum EH, Fry RD, et al. Locoregional recurrence and survival after curative resection of adenocarcinoma of the colon. J Am Coll Surg. 2002;195(1):33-40. 